Sources and contributors: Both authors have extensive experience in treating patients with myositis and are active in research, both clinical and fundamental, about myositis. The Neuromuscular Centre Nijmegen has an extensive collaboration with the departments of rheumatology, dermatology, and internal medicine, and through this collaboration the authors are familiar with the different viewpoints about diagnostic criteria, treatment, etc, for myositis. The source of information used to prepare the manuscript is outlined in the manuscript itself and consists of the medical literature in general. Both authors contributed to the format of the study, the data collection and analysis, and writing the manuscript. GH is guarantor.

Funding: None.

Competing interests: None declared.

1 Dalakas MC, Hohlfeld R. Polymyositis and dermatomyositis. Lance 2003;362:971-82.

2 Barohn RJ, Amato AA, Sahenk Z, Kissel JT, Mendell JR. Inclusion body myositis: explanation for poor response to immunosuppressive therapy. Neurology 1995;45:1302-4.

3 Amato AA, Gronseth GS, Jackson CE, Wolfe GI, Katz JS, Bryan WW, et al. Inclusion body myositis: clinical and pathological boundaries. Ann Neurol 1996;40:581-6.

4 Miller FW, Rider LG, Plotz PH, Isenberg DA, Oddis CV. Diagnostic criteria for polymyositis and dermatomyositis. Lancet 2003;362:1762-3.

5 Van der Meulen MFG, Bronner IM, Hoogendijk JE, Burger H, Van Venrooij WJ, Voskuyl AE, et al. Polymyositis: an overdiagnosed entity. Neurology 2003;61:316-21
6 Amato AA, Griggs RC. Unicorns, dragons, polymyositis, and other mythological beasts. Neurology 2003;61:288-90. al. Polymyositis: an overdiagnosed entity. Neurology 2004;63:402.

8 Bradley WG. Polymyositis: an overdiagnosed entity. Neurology 2004;63:402 Hengstman GJD, Van Engelen BGM. Polymyositis: an overdiagnosed entity. Neurology 2004;63:402-3.

10 Bohan A, Peter JB. Polymyositis and dermatomyositis (first of two parts). N Engl J Med 1975;292:344-7.

11 Carpenter S, Karpati G. The major inflammatory myopathies of unknown cause. Pathol Annu 1981;16:205-37.

12 Arahata K, Engel AG. Monoclonal antibody analysis of mononuclear cells in myopathies. I: Quantitation of subsets according to diagnosis and sited of accumulation and demonstration and counts of muscle fibers sited of accumulation and demonstration and
invaded by T cells. Ann Neurol 1984;16:193-208.

13 Ringel SP, Carry MR, Aguilera AJ, Starcevich JM. Quantitative histopathology of the inflammatory myopathies. Arch Neurol 1986;43:1004-9

14 Emslie-Smith AM, Arahata K, Engel AG. Major histocompatibility complex class I antigen expression, immunolocalization of interferon subtypes, and T cell-mediated cytotoxicity in myopathies. Hum Pathol 1989;20:224-31.

15 Van der Meulen MFG, Hoogendijk JE, Jansen GH, Veldman H, Wokke $\mathrm{JH}$. Absence of characteristic features in two patients with inclusion body myositis. J Neurol Neurosurg Psychiatry 1998;64:396-8.

16 Whitaker JN. Inflammatory myopathy: a review of etiologic and pathogenetic factors. Muscle Nerve 1982;5:573-92.

17 Hoogendijk JE, Amato AA, Lecky BR, Choy EH, Lundberg IE, Rose MR, et al. 119th ENMC international workshop: trial design in adult idiopathic inflammatory myopathies, with the exception of inclusion body myositis, 10-12 October 2003, Naarden, The Netherlands. Neuromuscul Disord 2004; 14:337-45.

\title{
Meeting mania 2004
}

\author{
David S Goldbloom
}

The rise in the number of meetings occurring every day in healthcare institutions shows no sign of abating. What are the factors contributing to this "meeting mania," and is there anything that can be done to counter it?

Ten years ago Abraham Bergman described the epidemic phenomenon in healthcare institutions of "meeting mania." He lamented the exponential increase in the frequency of meetings and ascribed it to the proliferation of administrators and managers. He observed that meetings served several illusory purposes: communication, decision making, and responsibility. He bravely called for a moratorium on meetings for 30 days and then a gradual and filtered reintroduction with better clarity of purpose, time limits, and format. He advocated email as a useful alternative to meetings, or voicemail for communication purposes.

What has the past decade wrought? From the perspective of a former physician-in-chief of an academic health sciences centre, meeting mania has become pandemic, rivaling the 1918 influenza outbreak. Meetings, task forces, and retreats (they are never advances) pervade our agendas more than ever before. In the past 10 years several phenomena have contributed to the worsening of this problem.

\section{Electronic wizardry}

Most of us have at least the skeleton of our daily schedules captured on software that is typically uniform throughout a hospital. In order to schedule meetings, this software has the capacity to search the schedules of all potential attendees to find common times when they are free; an email follows asking you to attend, smugly knowing that you have no conflicting commitments. Orwellian concerns that your schedule of daily activities is freely available to others notwithstanding, there is a fundamental assumption in this software that exacerbates meeting mania: if you are not "busy" as reflected by a scheduled event in your electronic calendar (typically a meeting), ergo you are not working. In fact, the opposite is probably true-the only time you may be doing productive work is when you are not in a meeting. Some colleagues have taken to blocking off time in their electronic schedules simply to render themselves impervious to the feeding frenzy of meeting schedulers.

Perhaps naively, Bergman hoped that email would serve as a better communication vehicle than face to face contact. At our hospital, it is not uncommon for senior managers to receive between 60 and 100 emails in a day. Answering email now counts as work. In the absence of a defined etiquette of electronic communication, the tyranny of distribution lists creates a barrage, at no extra cost to the sender, of information that may be only peripherally relevant to any individual recipient. Furthermore, the tragic alignment of the "reply to all" button adjacent to the "reply" button on the toolbar is a fundamental error of human engineering. It means that all too often one learns that a colleague is unable to attend a meeting to which 30 people have been invited or is simply saying, "Thanks." Who cares? Many of us succumb to the Sisyphean temptation of answering email as soon as it comes in, in the vain hope that the inbox will remain empty. It never does. More moderate souls reserve a time at the
Centre for

Addiction and Mental Health, 250 College Street, Toronto, ON, Canada M5T 1R8

David S Goldbloom senior medical adviser, education and public affairs david_goldbloom@ camh.net

BMJ 2004;329:1467-9 


\section{Summary points}

"Meeting mania" has increased since it was first described 10 years ago

Scheduling software and PowerPoint presentations exacerbate the problem, and email has done nothing to reverse it

External facilitators, SWOT analysis, and flipcharts with coloured dots purport to reveal the mysteries of the universe

Organisations endlessly refine their mission statements and strategic plans, generating a whole new vocabulary

Meetings should be for interactions rather than presentations, could be scheduled for less than an hour, and could take place in corridors after lunch

end of the day to deal with the emails that have come in over the previous 24 hours, so as to minimise both the intrusion on work and the confusion with work. This strategy can successfully elude time sensitive requests and allow problems to be resolved before your intervention. Because email is essentially a postcard with regard to confidentiality and is easily forwarded, extremely sensitive and confidential communication still requires human contact, as in the ominous curt email message that says simply, "Call me."

When we are unable to elude meetings, we can count on witnessing at least one PowerPoint presentation. This means that meetings need rooms with an LCD (liquid crystal display) projector and a screen to enable people to communicate with each other. Just a few years ago, slides were prepared at considerable time and expense and were used to present data or show images, lesions, or microscopic findings that defied simple verbal description. Now, through the seductive facility of intuitive software, electronic slides have devolved into speaker's notes-projected index cards. Instead of simply listening to and processing what the person is saying, the audience is now engaged

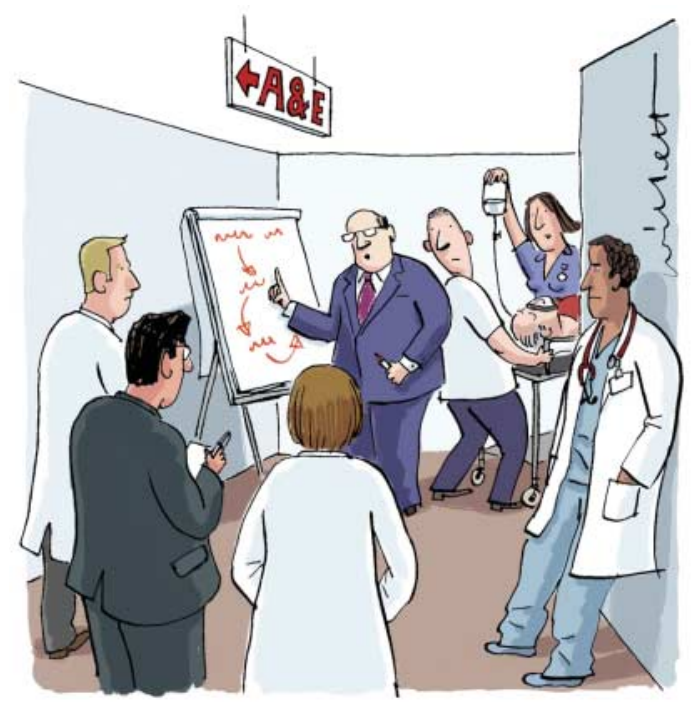

in the cognitive task of trying to correlate what they hear with the bullet points on the screen. This becomes a tripartite mission when they have also received a precirculated handout of the slides that often differs slightly from the on-screen presentation, thanks to the ease of last minute editing. The tyranny of these presentations has been the subject of a recent diatribe. ${ }^{2}$

\section{The art of facilitation}

An increasingly common feature of meetings in the past decade is the presence of a facilitator. Most commonly, these people are external to the organisation and have (proudly) no content expertise in the subject matter of the meeting. Rather, their expertise is in getting people to work together. This typically involves a combination of low tech and high tech solutions. After assignment of people to small working groups and some opening "icebreakers" to set a mood for creative thinking, the meeting begins. Using large flipcharts and marker pens, the group is asked to apply the "SWOT" (strengths, weaknesses, opportunities, threats) principle to the problem at hand; this parallels the "auto content wizard" in PowerPoint that designs presentations for you and is endlessly adaptable. Small groups delegate both recorders and reporters, and the latter are designated to provide feedback to the larger group, all under the watchful eye of the facilitator. Priorities for action may then be declared democratically by the assignment of different coloured dots to the flipcharts. Meal breaks for the participants are used by the facilitator to synthesise the work they have done. This may involve counting up the coloured dots (and ignoring the dimpled chads) and declaring the winning priorities for the group, or translating handwritten scrawl on flipcharts to either a word processing program or a slide show. Thus are the mysteries of the universe revealed.

\section{Mission impossible}

Retreats typically have two related purposes: to develop a statement of mission, vision, and core values and to propagate a strategic plan. These can consume senior managers while remaining invisible to the rest of the organisation. It is hard to believe that hospitals limped along for centuries without defined, honed, and articulated mission, vision, and core values. How did doctors and nurses ever know what they were supposed to be doing?

One can usually count on the first hour involving a Talmudic debate over the semantic differences between a mission and a vision, for the benefit of the uninitiated. Then the better part of a day can be spent in splitting prepositions and encumbering with adjectives, resulting in a variant of the mission on the television space adventure show Star Trek ("To boldly go"). Because the English language was desperately short of verbs, this exercise is now commonly called "wordsmithing" and involves healthcare workers and administrators acquiring instant expertise in syntax, communication, and marketing.

This new lexicon involves words and phrases such as synergy, opportunity costs, core competencies, iterative processes, taking issues offline, stakeholder needs, crystal-balling, and blue-skying. If you are looking for an excuse to avoid daytime encounters with the 
purveyors of such jargon, another buzz phrase provides the opportunity; the now widespread use of the introductory summative words "at the end of the day" suggests that the important conclusions occur mainly in the evening.

\section{Coping strategies}

Bergman's wish for a moratorium on meetings was, in retrospect, quixotic. However, some strategies for meetings may minimise their impact on real work. These might include conducting meetings standing up in hallways, as it is often in the corridors of power that true decisions are made. Meetings should not occur until after lunch, so people can get some reflective or clinical work done at the beginning of the day. The minimum unit of measurement for a meeting should be reduced from an hour to 15 minutes, given the natural tendency of meetings to fill the available time. Meetings should be for interactions, not for presentations; people can prepare for meetings by reading the material and deciding if they really need to be there, rather than discovering by attending that they did not need to do so. People who chair meetings and lose control of the agenda and the duration should have this reflected in their performance appraisal. Finally, leaders should tally monthly the amount of time they spend in meetings and then ask themselves soberly if this is the optimal use of their time and talents.

We are profoundly unlikely to revert to the pre-corporate era of health care. Healthcare workers who aspire to positions of leadership in healthcare institutions feel increasingly naked without at least an executive MBA degree if not the real McCoy. Or perhaps this is the adolescence of our business evolution, where we eagerly adopt the fashion in the belief that it has deeper meaning and is the only way to be accepted in academic high society. Watch this space in a decade for a fashion update.

Competing interests: None declared.

1 Bergman AB. Meeting mania. N Engl J Med 1994;330:1622-3.

2 Tufte ER. The cognitive style of PowerPoint. Cheshire, CT: Graphics Press LLC, 2003.

\section{How to get your paper rejected}

These days, if you do not publish, you perish. Well, you don't perish, but you do not get promotions. With promotions come more responsibilities, more paperwork, more income tax. If you want to stay comfortably in your position, you should not publish. Here are a few tips to get your papers eternally rejected. Proving the efficacy of the method, this article was rejected by the Lancet on 14 May 2004, by the New England Journal of Medicine on 19 May 2004, by JAMA on 27 May 2004, by Science on 24 June 2004, by the Proceedings of the National Academy of Sciences of the United States of America on 29 June 2004, and by Nature on 30 June 2004. Getting started

Start by looking at your data randomly. Something will come out. Why bother with writing a protocol when you already have results?

Be imaginative when writing the title. Put marketing before science. Attract the reader with the promise of an answer you don't have.

Use fancy words.

\section{Questions and answers}

In the abstract, ask as many questions as you can. Show them how broad your interests are.

Come up with a creative answer to a question, any question.

Answers always look nice.

In the introduction, criticise the work of possible reviewers. Be particularly nasty. This is your chance for revenge.

Do a very extensive discussion of the literature in the introduction. They may not like your results, but they may publish it as a review.

Use more fancy words.

As for the materials and methods, sample size calculation is an imperfect science. Calculate the sample size needed based in the size of your sample.

\section{Descriptions}

Describe your methods in random order. Who cares, as long as all the information is there.

Do not describe your methods in detail. The readers of major journals should know better what you are talking about.

Be careful not to give many details. The section will be confusing, and if somebody repeats your experiments he or she may get a different result. You do not have time for controversy.

Use even more fancy words.
Show every single result that you have obtained (or found in the records, actually). Show how thorough you have been in your search for data.

Again, describe your results in random order. You may order them alphabetically.

Have your 4 year old daughter proofread your spelling, and your 2 year old son proofread the grammar.

\section{What you know}

Critically discuss your results, comparing them with others'. I mean being critical of others. This is your second chance for revenge.

You know your conclusions make sense. Do not bother with explaining why.

You know your data are good. You have spent a lot of time copying those darn numbers from the charts. They should support your conclusions.

You know that results often tell more than what is evident. Feel free to draw imaginative conclusions.

\section{The right answer}

What you think is obviously the answer, must be the right answer. Do not look for alternative explanations that will make everything even more confusing.

List references, many references. Copy references from other papers. Do not bother reading the actual articles. If they are published, they have to be accurate.

Do not bother following the journal style for references. You can always change that later.

Add five or six charts. Better still, put in several tables cluttered with numbers. That way, you make sure that nobody will read them.

\section{A work of art}

Do not revise your paper. Think of it as a work of art, that is how it came out of your brain in the first place.

And, finally, my best advice of all:

Get the name of the editor in chief wrong-or get it right, but misspell it.

Horacio Plotkin assistant professor of paediatrics and orthopaedics, University of Nebraska Medical Center, Omaha, USA

(hplotkin@unmc.edu) 